\title{
Article \\ The Evolution of Fluoroquinolone Resistance in Salmonella under Exposure to Sub-Inhibitory Concentration of Enrofloxacin
}

\author{
Yufeng Gu ${ }^{1,2}$, Lulu Huang ${ }^{1,2}$, Cuirong Wu ${ }^{1,2}$, Junhong Huang ${ }^{1,2}$, Haihong Hao 1,2 $\mathbb{D}$, Zonghui Yuan 1,2 \\ and Guyue Cheng 1,2,*
}

1 College of Veterinary Medicine, Huazhong Agricultural University, Wuhan 430070, China; guyufeng@webmail.hzau.edu.cn (Y.G.); huanglu@webmail.hzau.edu.cn (L.H.); wcrvary@outlook.com (C.W.); huangjunhong@webmail.hzau.edu.cn (J.H.); haohaihong@mail.hzau.edu.cn (H.H.); zonghuiyuan@mail.hzau.edu.cn (Z.Y.)

2 MOA Laboratory for Risk Assessment of Quality and Safety of Livestock and Poultry Products, Huazhong Agricultural University, Wuhan 430070, China

* Correspondence: chengguyue@mail.hzau.edu.cn; Tel.: +86-027-8728-7165

check for updates

Citation: Gu, Y.; Huang, L.; Wu, C.; Huang, J.; Hao, H.; Yuan, Z.; Cheng, G. The Evolution of Fluoroquinolone Resistance in Salmonella under Exposure to Sub-Inhibitory Concentration of Enrofloxacin. Int. J. Mol. Sci. 2021, 22, 12218. https://doi.org/10.3390/ ijms222212218

Academic Editor: Ismail Fliss

Received: 7 October 2021

Accepted: 2 November 2021

Published: 11 November 2021

Publisher's Note: MDPI stays neutral with regard to jurisdictional claims in published maps and institutional affiliations.

Copyright: (c) 2021 by the authors. Licensee MDPI, Basel, Switzerland. This article is an open access article distributed under the terms and conditions of the Creative Commons Attribution (CC BY) license (https:// creativecommons.org/licenses/by/ $4.0 /)$.

\begin{abstract}
The evolution of resistance in Salmonella to fluoroquinolones (FQs) under a broad range of sub-inhibitory concentrations (sub-MICs) has not been systematically studied. This study investigated the mechanism of resistance development in Salmonella enterica serovar Enteritidis (S. Enteritidis) under sub-MICs of $1 / 128 \times$ MIC to $1 / 2 \times$ MIC of enrofloxacin (ENR), a widely used veterinary FQ. It was shown that the resistance rate and resistance level of $S$. Enteritidis varied with the increase in ENR concentration and duration of selection. qRT-PCR results demonstrated that the expression of outer membrane porin (OMP) genes, ompC, ompD and $o m p F$, were down-regulated first to rapidly adapt and develop the resistance of $4 \times \mathrm{MIC}$, and as the resistance level increased $(\geq 8 \times \mathrm{MIC})$, the upregulated expression of efflux pump genes, $a c r B, \operatorname{emr} B$ amd $m d f A$, along with mutations in quinolone resistance-determining region (QRDR) gradually played a decisive role. Cytohubba analysis based on transcriptomic profiles demonstrated that $\operatorname{purB}, \operatorname{purC}, \operatorname{purD}, \operatorname{purF}, \operatorname{purH}$, purK, purL, purM, purN and purT were the hub genes for the FQs resistance. The 'de novo' IMP biosynthetic process, purine ribonucleoside monophosphate biosynthetic process and purine ribonucleotide biosynthetic process were the top three biological processes screened by MCODE. This study first described the dynamics of FQ resistance evolution in Salmonella under a long-term selection of sub-MICs of ENR in vitro. In addition, this work offers greater insight into the transcriptome changes of $S$. Enteritidis under the selection of ENR and provides a framework for FQs resistance of Salmonella for further studies.
\end{abstract}

Keywords: Salmonella; enrofloxacin; resistance; sub-inhibitory concentration; transcriptome sequencing

\section{Introduction}

Salmonella enterica serovar Enteritidis (S. Enteritidis), a zoonotic foodborne pathogen, has been widely recognized as one of the most common causes of gastroenteritis in humans [1]. According to the report of World Health Organization, Salmonella enterica serovar Typhimurium (S. Typhimurium) and $S$. Enteritidis are the most frequently isolated Salmonella serotypes from countries involved in the Global Foodborne Infections Network [2]. Fluoroquinolones (FQs) have been broadly applied in clinical practice for treating Salmonellosis in both humans and animals [3,4]. The emergence of resistance to FQs has become a critical problem in clinical treatment of Salmonellosis [5].

The mechanisms of FQs resistance in Salmonella include point mutations in quinolone resistant determining regions (QRDRs) in gyrA, gyrB, parC and parE [6]. Additionally, decreased intake as well as increased efflux of FQs adds to the resistant phenotype of Salmonella. For example, changes in outer membrane porins (OMPs) (e.g., OmpC, OmpD and OmpF) [7] and elevated expression of multidrug resistance (MDR) efflux pumps (e.g., AcrAB, AcrEF, EmrAB, MdfA and MdtK) [8] of Salmonella has been demonstrated 
as resistance mechanism to FQs for both clinical resistant isolates and resistant clones de novo selected by increasing concentrations (above MIC) of FQs in vitro [9]. However, the time sequence of the emergence of these various resistance mechanisms and the correlation with the level of resistance and the pressure of different antibiotic concentration is unclear and remains to be studied in detail.

Antimicrobials at sub-inhibitory concentrations (sub-MICs) are commonly found in patients, livestock and the environment, often at a wide concentration ranging from $1 / 4$ to $1 / 230$ of the MIC $[10,11]$. However, previous understanding of the resistance evolution process is mostly based on mutants selected by incrementally increasing antibiotic concentrations within mutant selection windows (MSW) [12,13]. It has been shown that de novo mutants can be selected at sub-MIC of antimicrobials associated with several secondary effects, such as inducing the SOS response, stimulating the production of reactive oxygen species, increasing the frequency of errors in protein synthesis, increasing the rates of recombination and horizontal gene transfer, etc. [14-18].

Recent work has shown that the resistance mechanisms induced by sub-MIC exposure may be different compared to selection with antibiotics concentration above MIC. In $S$. Enteritidis, high-level resistance was selected by sub-MICs of streptomycin through multiple small-effect resistance mutations, whereas specific target mutations were generated under selection with antibiotics concentration above MIC [19]. While many studies have investigated the resistance mechanism of bacteria under a short-term exposure to antibiotics [20,21], less is known about the effects of long-term exposure to sub-MIC of antibiotics. When exploring the de novo high-level or clinical resistance to the antimicrobial agent, most of these reports are endpoint observations and seldom take into account the changes occurring during the resistance evolution process. A more comprehensive understanding of the resistance development trajectory could help overcome resistance emergence.

Here, we systematically explored the resistance evolution of $S$. Enteritidis during longterm exposure to a wide range of sub-MICs $(1 / 128 \times \mathrm{MIC}$ to $1 / 2 \times \mathrm{MIC})$ of enrofloxacin (ENR) and compared the effect of several concentration of ENR on the origin of resistance, focusing on the resistance mechanism to ENR. The known resistance mechanisms associated with de novo antibiotic resistance were analyzed in this study, including QRDRs of $g y r A, g y r B$, parC and parE genes, expression levels of the OMPs and MDR efflux pump genes. Transcriptome profiles of $S$. Enteritidis mutants with MIC level of $32 \times \mathrm{MIC}$, $16 \times \mathrm{MIC}$ and $8 \times \mathrm{MIC}$ were compared to the $S$. Enteritidis parental strain, giving an indication of the resistance evolution route and molecular mechanism of $S$. Enteritidis under exposure to ENR in the long term. Therefore, the purpose of this study was to determine the role of different resistance mechanisms under a selection of sub-MICs of ENR during the resistance development term. Overall, our findings added to evidence that sub-MIC antibiotic exposure and long-term selection prime bacteria for reduced susceptibility and resistance evolution.

\section{Results}

\subsection{Resistance Development of S. Enteritidis under Exposure to sub-MICs of ENR In Vitro}

The MIC of ENR for the parental S. Enteritidis CICC21527 strain was determined to be $0.0625 \mu \mathrm{g} / \mathrm{mL}$. When exposed to sub-MICs of ENR, a gradual increase in the size of reduced susceptibility subpopulations was appeared during 600 generations, while no decrease in susceptibility was observed in the absence of ENR (Figure 1). Obviously, de novo generated resistant mutants could be selectively enriched in a wide range of ENR. Furthermore, the selection acted more efficiently for a higher ENR concentration to select for resistance. At sub-MIC of ENR, the rapid enrichment of de novo-resistant mutants was observed. Thus, within 100 to 600 generations, a considerable enrichment of mutants with resistances between two and four times the MIC of the parental strain could be seen and also, after 300 to 600 generations, a high level reduced susceptibility mutants $(8 \times \mathrm{MIC})$ that appeared. After 400 generations, subpopulations with a MIC higher than $1 \mu \mathrm{g} / \mathrm{mL}$ $(16 \times$ MIC) were observed. Except $1 / 64 \times$ MIC and $1 / 128 \times$ MIC induction groups, all of 
the lineages had subpopulations with an MIC value higher than $1 \mu \mathrm{g} / \mathrm{mL}(16 \times \mathrm{MIC})$ after 600 generations. A total of $32 \times$ MIC-resistant subpopulations could only be selected by $1 / 2 \times$ MIC concentration of ENR at 600 generations. This showed an association between the concentrations of ENR and resistance occurrence rates as well as resistance levels of the mutant subpopulation.
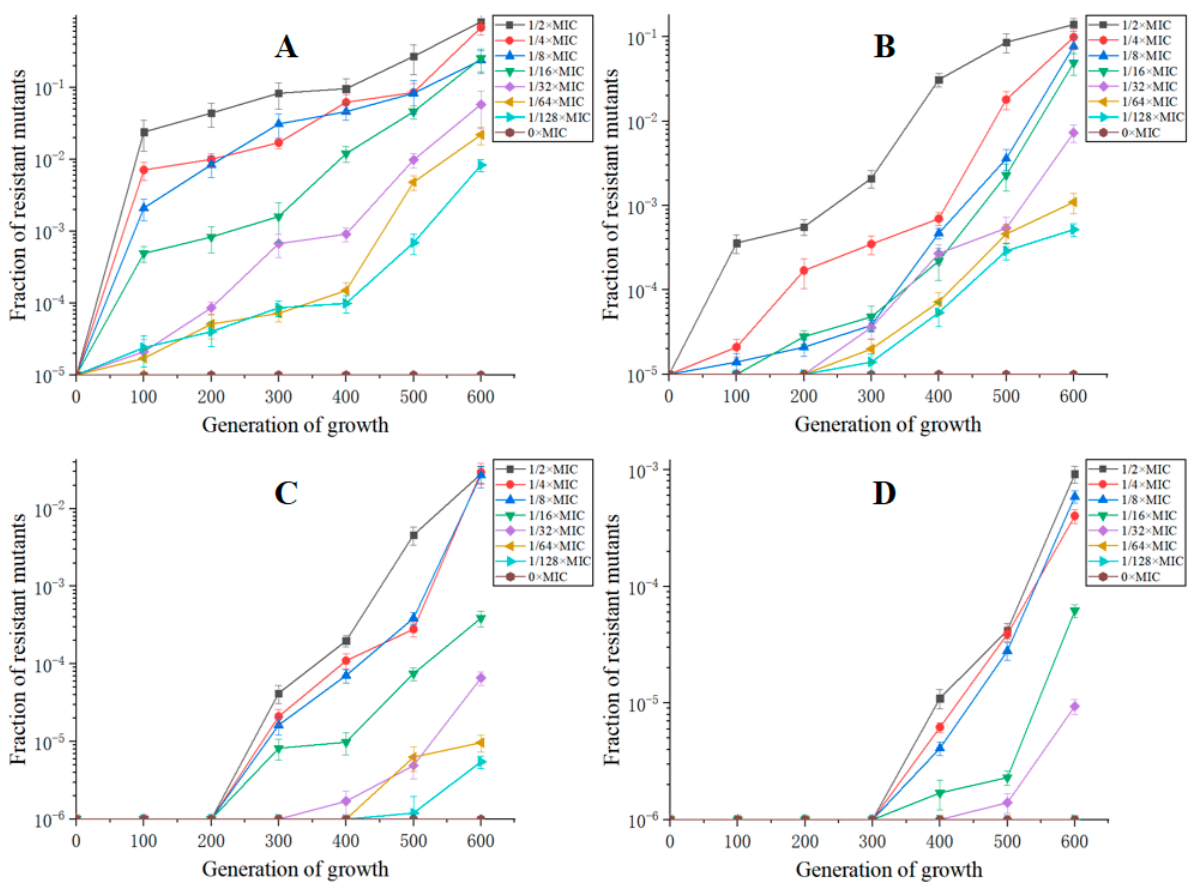

Figure 1. Resistance rates of $S$. Enteritidis CICC21527 exposed to sub-MICs of ENR at resistance level of $2 \times \operatorname{MIC}(\mathbf{A}), 4 \times \mathrm{MIC}($ B), $8 \times \mathrm{MIC}(\mathrm{C})$ and $16 \times \mathrm{MIC}(\mathrm{D})$.

\subsection{Mutations in the QRDRs of the Mutants with Reduced Susceptibility to ENR}

Compared to the parental strain, 12 out of 16 strains exhibiting MICs of 2 to $16 \times$ MIC had a mutation in the QRDR of the gyrA gene (Table 1). Among them, the mutation of Ser83Tyr was the most frequent $(n=6)$, followed by the mutations of Ser83Phe $(n=5)$ and Asp87Gly $(n=2)$. It was also demonstrated that mutation in $g y r A$ was not found in all reduced susceptibility mutants $(\leq 8 \times \mathrm{MIC})$, while mutation was presented in all resistant mutants $(\geq 16 \times$ MIC). No mutations in the QRDRs of $g y r B$, parC and parE were observed.

Table 1. Mutation sites in the QRDRs of $g y r A$, gyrB, parC, and parE genes of $S$. Enteritidis mutants.

\begin{tabular}{|c|c|c|c|c|c|}
\hline \multirow{2}{*}{ Strain Number } & \multirow{2}{*}{$\operatorname{MIC}(\mu \mathrm{g} / \mathrm{mL})$} & \multicolumn{4}{|c|}{ Substitutions in QRDR Amino Acid Residues } \\
\hline & & gyrA & gyrB & parC & parE \\
\hline $2 \mathrm{M}(1 / 2 \mathrm{M})$ & 0.125 & wt & wt & wt & wt \\
\hline $2 \mathrm{M}(1 / 8 \mathrm{M})$ & 0.125 & Asp87Gly & wt & wt & wt \\
\hline $2 \mathrm{M}(1 / 32 \mathrm{M})$ & 0.125 & wt & wt & wt & wt \\
\hline $2 \mathrm{M}(1 / 128 \mathrm{M})$ & 0.125 & Ser83Tyr & wt & wt & wt \\
\hline $4 \mathrm{M}(1 / 2 \mathrm{M})$ & 0.25 & wt & wt & wt & wt \\
\hline $4 \mathrm{M}(1 / 8 \mathrm{M})$ & 0.25 & Ser83Phe & wt & wt & wt \\
\hline $4 \mathrm{M}(1 / 32 \mathrm{M})$ & 0.25 & Ser83Tyr & wt & wt & wt \\
\hline $4 \mathrm{M}(1 / 128 \mathrm{M})$ & 0.25 & Ser83Tyr & wt & wt & wt \\
\hline $8 \mathrm{M}(1 / 2 \mathrm{M})$ & 0.5 & wt & wt & wt & wt \\
\hline $8 \mathrm{M}(1 / 8 \mathrm{M})$ & 0.5 & Ser83Phe & wt & wt & wt \\
\hline $8 \mathrm{M}(1 / 32 \mathrm{M})$ & 0.5 & Ser83Phe & wt & wt & wt \\
\hline $8 \mathrm{M}(1 / 128 \mathrm{M})$ & 0.5 & Asp87Gly & wt & wt & wt \\
\hline $16 \mathrm{M}(1 / 2 \mathrm{M})$ & 1 & Ser83Phe & wt & wt & wt \\
\hline $16 \mathrm{M}(1 / 8 \mathrm{M})$ & 1 & Ser83Phe & wt & wt & wt \\
\hline $16 \mathrm{M}(1 / 32 \mathrm{M})$ & 1 & Ser83Tyr & wt & wt & wt \\
\hline $32 \mathrm{M}(1 / 2 \mathrm{M})$ & 2 & Ser83Tyr & wt & wt & wt \\
\hline
\end{tabular}




\subsection{Expression of OMPs and MDR Efflux Pump Transporters of the Mutants with Reduced Susceptibility to ENR}

The expression of the OMP genes, ompC, ompD, ompF and genes encoding MDR efflux pump transporters, $a c r B, a c r F, e m r B, m d f A, m d t K$ of mutants was shown in Figure 2. In the mutants with susceptibility level less than $8 \times \mathrm{MIC}$, the expression of ompC, ompD and $о m p F$ were down regulated, and the amount of down-regulation decreased with the increase in resistance level. When the susceptibility level was more than $8 \times \mathrm{MIC}$, the expression of отрC $\mathrm{C}$ and $о т p D$ shifted to up-regulation, while the expression of $o m p F$ remained downregulated. The result showed that the expression of $o m p F$ was well correlated with the selected concentration of ENR.

In general, $a c r B, e m r B$ and $m d f A$ were down regulated in the $2 \times \mathrm{MIC}$ mutants. When the susceptibility level was equal or greater than $4 \times \mathrm{MIC}$, these three genes turned to up-regulated expression, and the expression level increased with the increase in resistance level with $a c r B$ gene exhibiting a higher level of up-regulation compared to those of the emrB and $m d f A$ genes (Figure 2). The expression of the other two MDR efflux pump transporter genes, $a c r F$ and $m d t K$, displayed a more strain dependent pattern in the reduced susceptible mutants, most of which showed up-regulation of $a c r F$ and $m d t K$ genes in the $2 \times$ MIC mutants and down regulation in mutants with resistant level $\geq 4 \times \mathrm{MIC}$, and as the resistance level increased, the expression of these two genes gradually decreased.
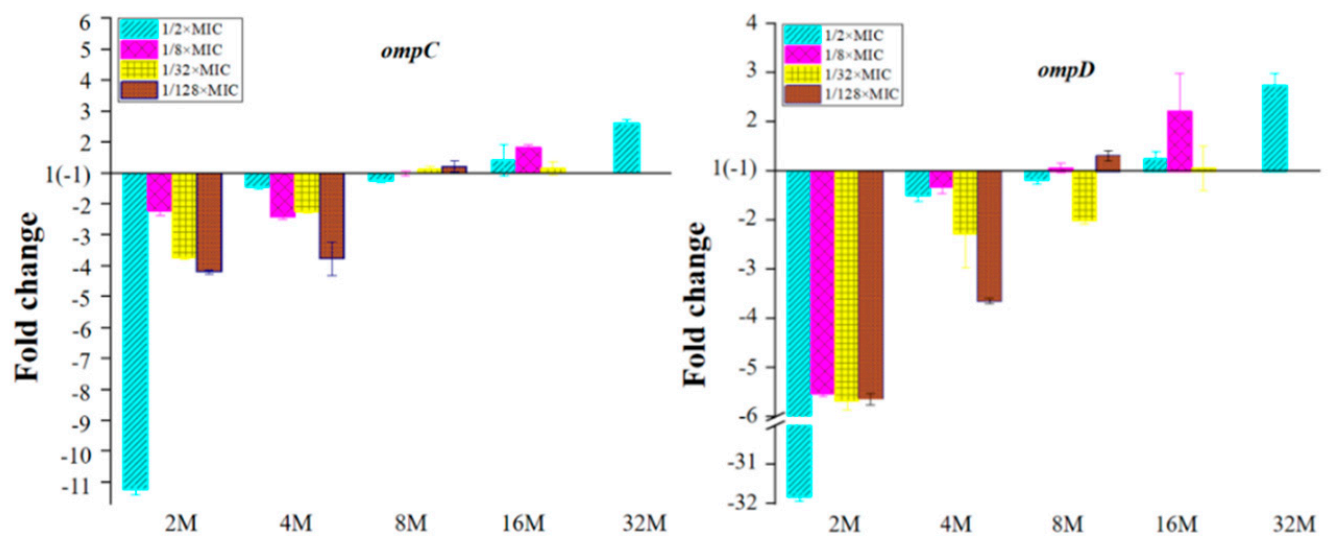

Antimicrobial susceptibility level

Antimicrobial susceptibility level
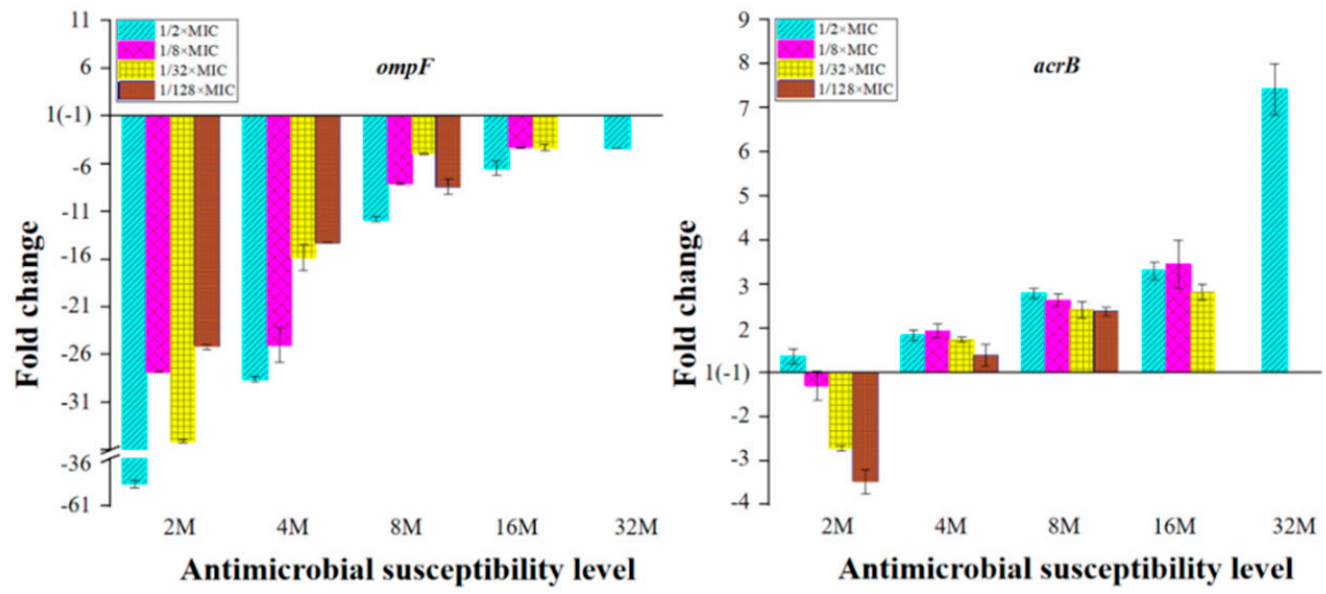

Figure 2. Cont. 

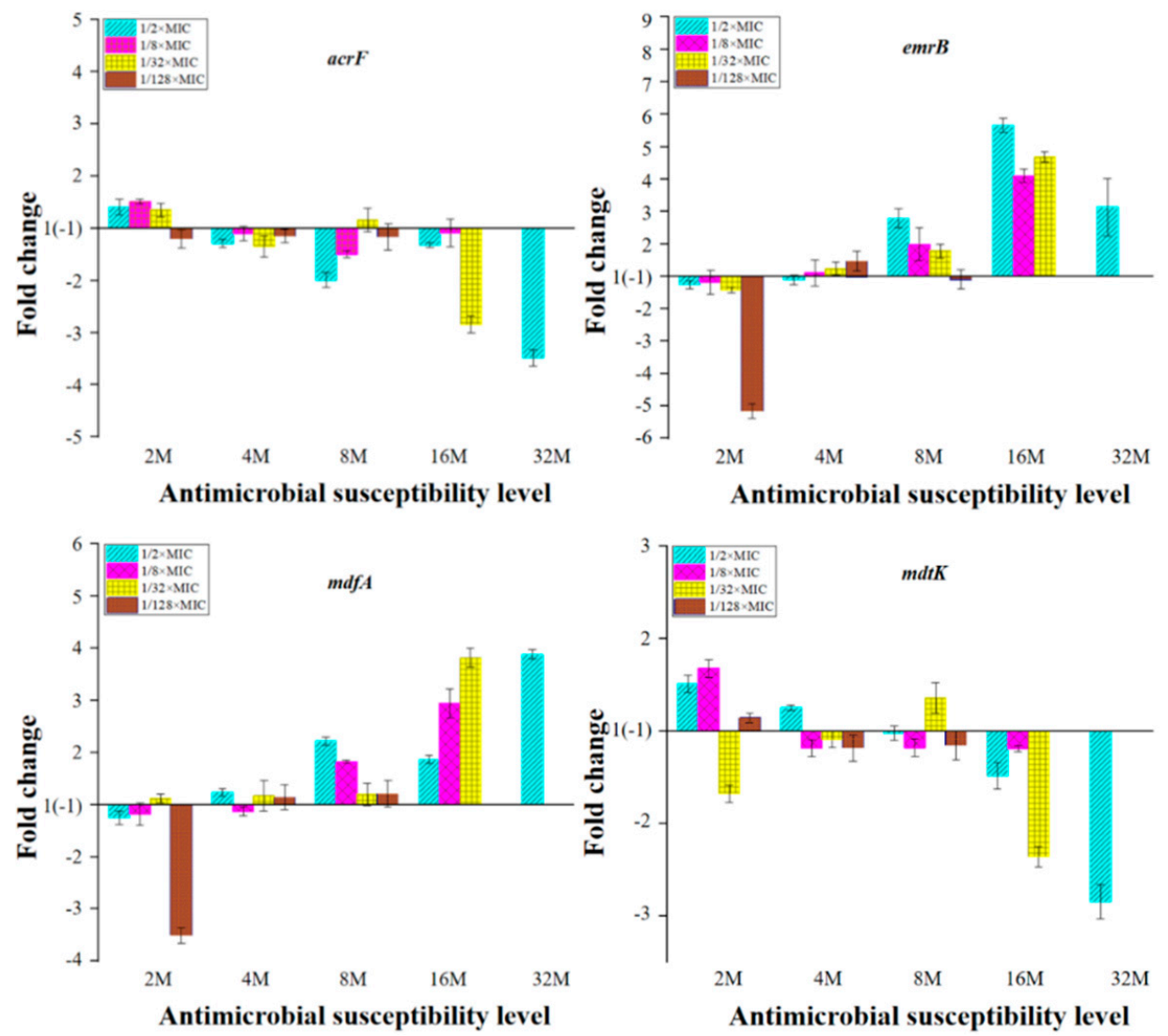

Figure 2. mRNA expression levels of the OMPs and MDR efflux pump transporter genes in Salmonella. Fold change $=2^{-\Delta \Delta \mathrm{CT}}, \Delta \Delta \mathrm{Ct}=\left(\mathrm{CT}_{\text {target }}-\mathrm{CT}_{\text {gap } A}\right)_{\text {mutant }}-\left(\mathrm{CT}_{\text {target }}-\mathrm{CT}_{\text {gap } A}\right)_{\text {parental }} .2 \mathrm{M}, 4 \mathrm{M}, 8 \mathrm{M}$, $16 \mathrm{M}$ represent $2 \times$ MIC mutants, $4 \times$ MIC mutants, $8 \times$ MIC mutants, $16 \times$ MIC mutants, respectively.

\subsection{Transcriptomic Profiles of S. Enteritidis Mutants Induced by sub-MICs of ENR}

Reduced susceptible mutant 8M (1/128M) (Group E), resistant mutant 16M (1/32M) (Group D) and 32M (1/2M) (Group C), and parental strain (Group B) were selected for analysis of transcriptomic profiles. The Pearson correlation coefficient of gene expression level in each group was greater than 0.91 , indicating that the correlation in gene expression level between triplicate samples in the same group was good (Figure S1). Compared to the parental strain, 2040 differentially expressed genes (DEGs) (1032 up-regulated and 1008 down-regulated) were found in the resistant mutant 32M (1/2M), 1497 DEGs (723 upregulated and 774 down-regulated) in resistant mutant $16 \mathrm{M}(1 / 32 \mathrm{M})$ and 1196 DEGs (644 up-regulated and 552 down-regulated) in reduced susceptibility mutant $8 \mathrm{M}(1 / 128 \mathrm{M})$. Compared to the parental strain, there were 573 co-differentially expressed genes (co-DEGs) among the three mutants; 333 genes were up-regulated and 240 genes were down-regulated in mutant 32M (1/2M); 300 genes were up-regulated and 273 genes were down-regulated in mutant $16 \mathrm{M}(1 / 32 \mathrm{M}) ; 298$ genes were up-regulated and 275 genes were down-regulated in mutant $8 \mathrm{M}(1 / 128 \mathrm{M})$.

The 573 co-DEGs were enriched in $24 \mathrm{GO}$ terms, including ribosome, purine nucleobase biosynthetic process, etc (Figure S2). Ninety-six common KEGG pathways were obtained, including ribosome, arginine and proline metabolism, nitrotoluene degradation, lysine degradation, tryptophan metabolism, fructose and mannose metabolism, PTS system, etc (Figure S3). Based on the information in the STRING protein query from public databases, 338 co-DEGs were mapped with the reference species of S. enterica CT18. Then, 120 genes were obtained probably related to the mechanism of FQs resistance according to the annotation of Non-Redundant Protein Sequence Database. GO function (Kappa score $\geq 0.8)$ and KEGG pathway $(p \leq 0.05)$ enrichment analyses of 120 candidate co-DEGs were performed with clueGO (Figure 3 ). It was shown that these genes were classified into 
14 functional categories including nucleoside metabolic, purine nucleobase biosynthetic process, nuclebase-containing compound biosynthetic process, hydroxymethyl-, formyland related transferase activity, tricarboxylic acid cycle, short-chain fatty acid metabolic, nuclebase-containing compound metabolic process, chromosome, DNA topological change, purine ribonucleoside triphosphate binding, organelle organization, RNA binding, RNA catabolic process, purine-containing compound biosynthetic process (Figure 3A). The metabolic pathways were significantly enriched in one carbon pool by folate, purine metabolism, propanoate metabolism, citrate cycle (TCA cycle) and RNA degradation pathways (Figure 3B).

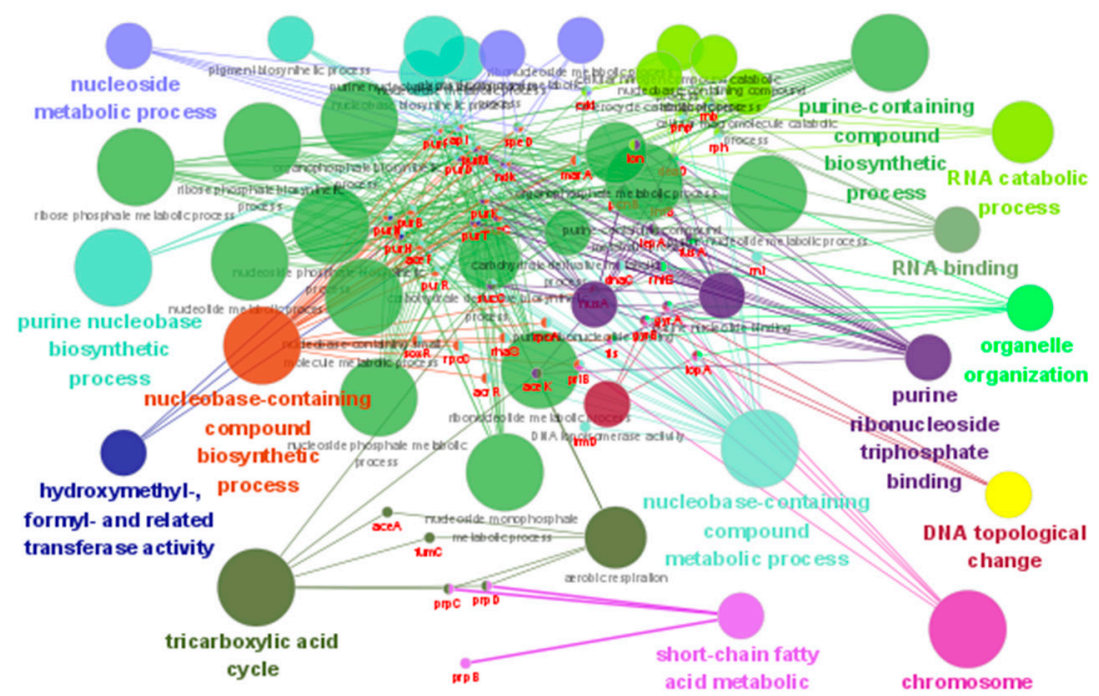

(A)

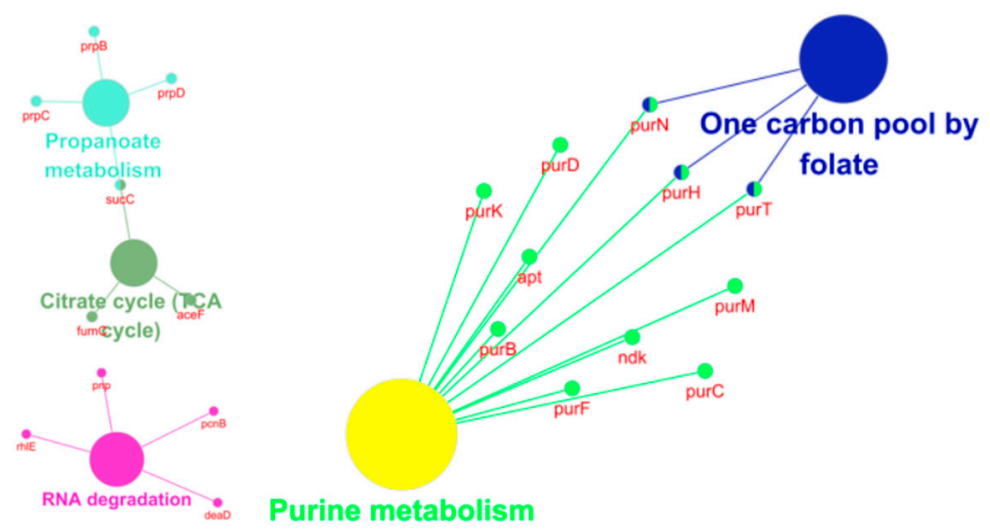

(B)

Figure 3. Enrichment analysis of GO and KEGG of genes that may be related to ENR resistance by ClueGO. GO term enrichment (A); KEGG enrichment (B).

The 120 genes mentioned above encoding proteins belonging to the oxidoreductase, purine and pyrimidine metabolism, cell division, transcriptional regulator, stress response protein, DNA topoisomerase, DNA and RNA polymerase, RND efflux transporter were screened to identify molecular determinants associated with the response to ENR in Salmonella. With the aim of identifying key or central genes in the co-DEGs network of the $S$. Enteritidis mutants after exposure to sub-MICs of ENR, an analysis of hub gene identification was conducted based on STRING database (Figure 4A). 


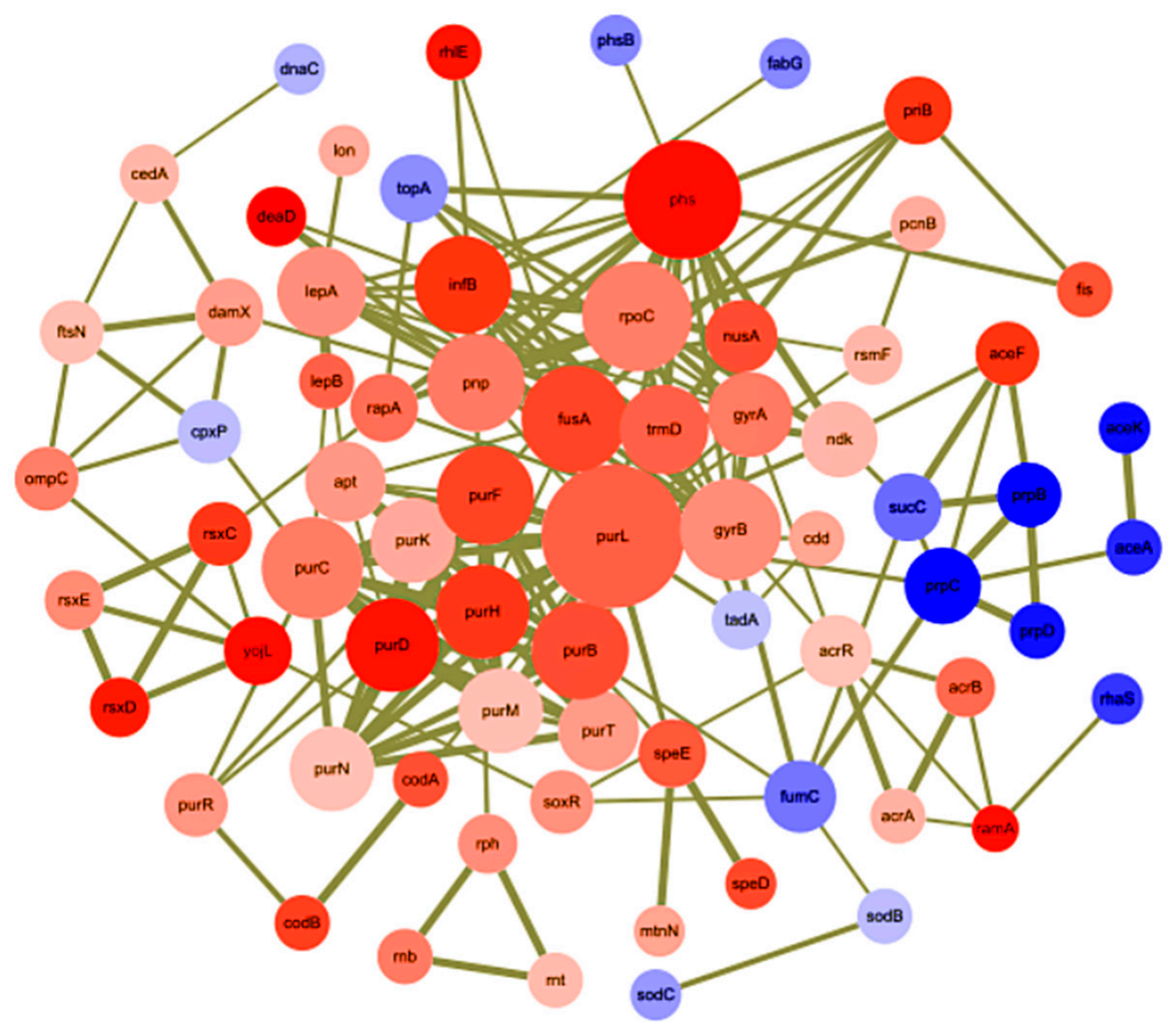

(A)

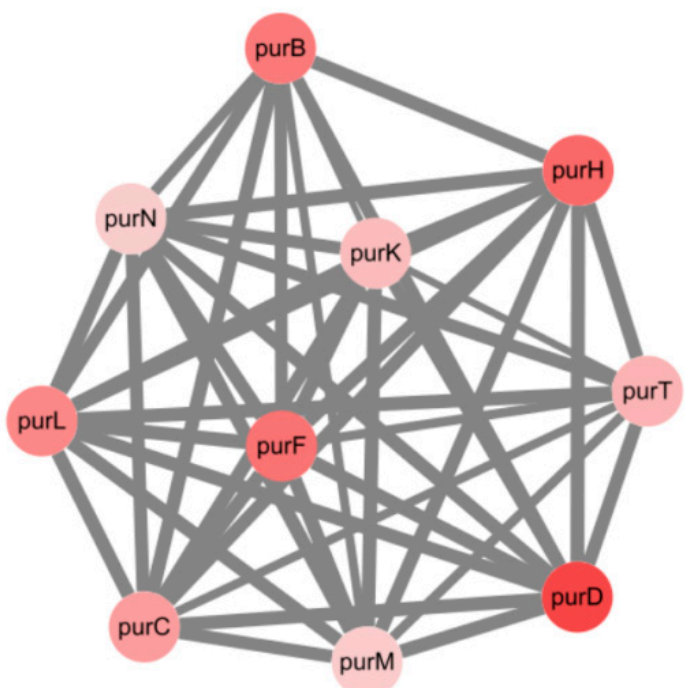

(B)

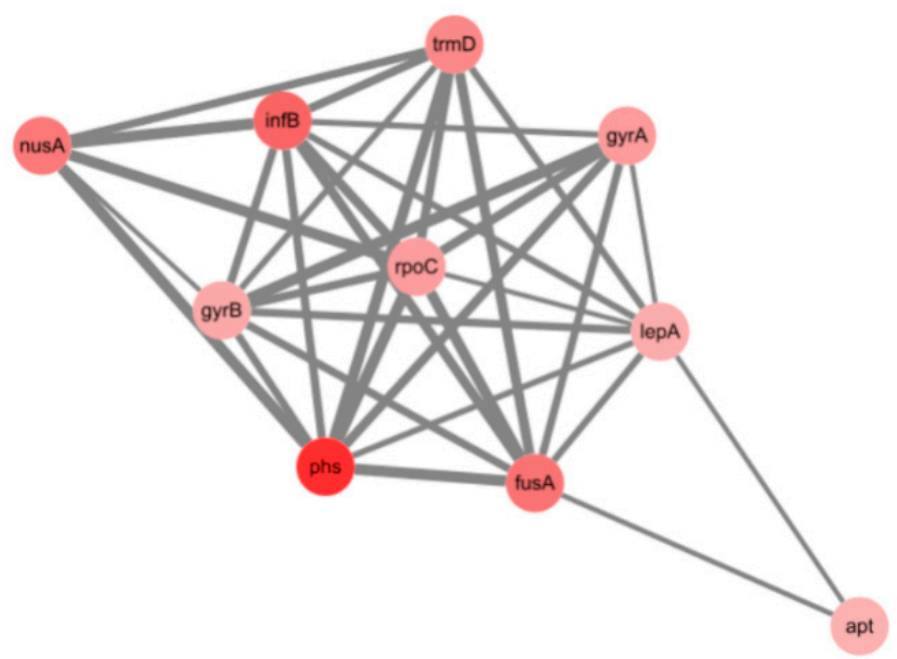

(C)

Figure 4. Network analysis of co-DEGs selected for underlying resistance mechanism. (A) Using the STRING online database, total of 120 co-DEGs were filtered into the PPI network and visualized by Cytoscape; (B,C) top two PPI networks in MCODE analysis.

Furthermore, the Cytohubba result showed that purB, purC, purD, purF, purH, purK, purL, purM, purN and purT were the hube genes that responded to sub-MICs of ENR. To better understand the potential biological mechanism related to the network, screened the top two clusters was screened by MCODE with the highest clustering scores (Figure 4B,C) and the main biological processes (Table 2). 
Table 2. Enrichment analysis of the top 2 MCODE genes function.

\begin{tabular}{ccc}
\hline MCODE & GO & Description \\
\hline MCODE-1 & GO:0006189 & False Discovery Rate \\
MCODE-1/MCODE-2 & GO:0009168 & Purine ribonucleoside monophosphate biosynthetic process \\
MCODE-1/MCODE-2 & GO:0009152 & Purine ribonucleotide biosynthetic process \\
MCODE-1/MCODE-2 & GO:0034641 & Cellular nitrogen compound metabolic process \\
MCODE-1/MCODE-2 & GO:0044271 & Cellular nitrogen compound biosynthetic process \\
\hline
\end{tabular}

The 39 DEGs out of the 120 co-DEGs selected by the criteria of expression fold-changes more than or equal to twice between these groups were selected for candidated key genes for their differential expression between mutants 32M (1/2M), 16M (1/32M) and 8M $(1 / 128 \mathrm{M})$ (Table S1). These genes were further screened and the heatmap was showed in Figure 5, then STRING database was used to achieve the cluster map. In total, ten clusters were identified including purine biosynthesis, purine biosynthesis, and pyrimidine metabolism, 'de novo' IMP biosynthetic process, response to antibiotic and transcription regulator, DNA topoisomerase, etc.

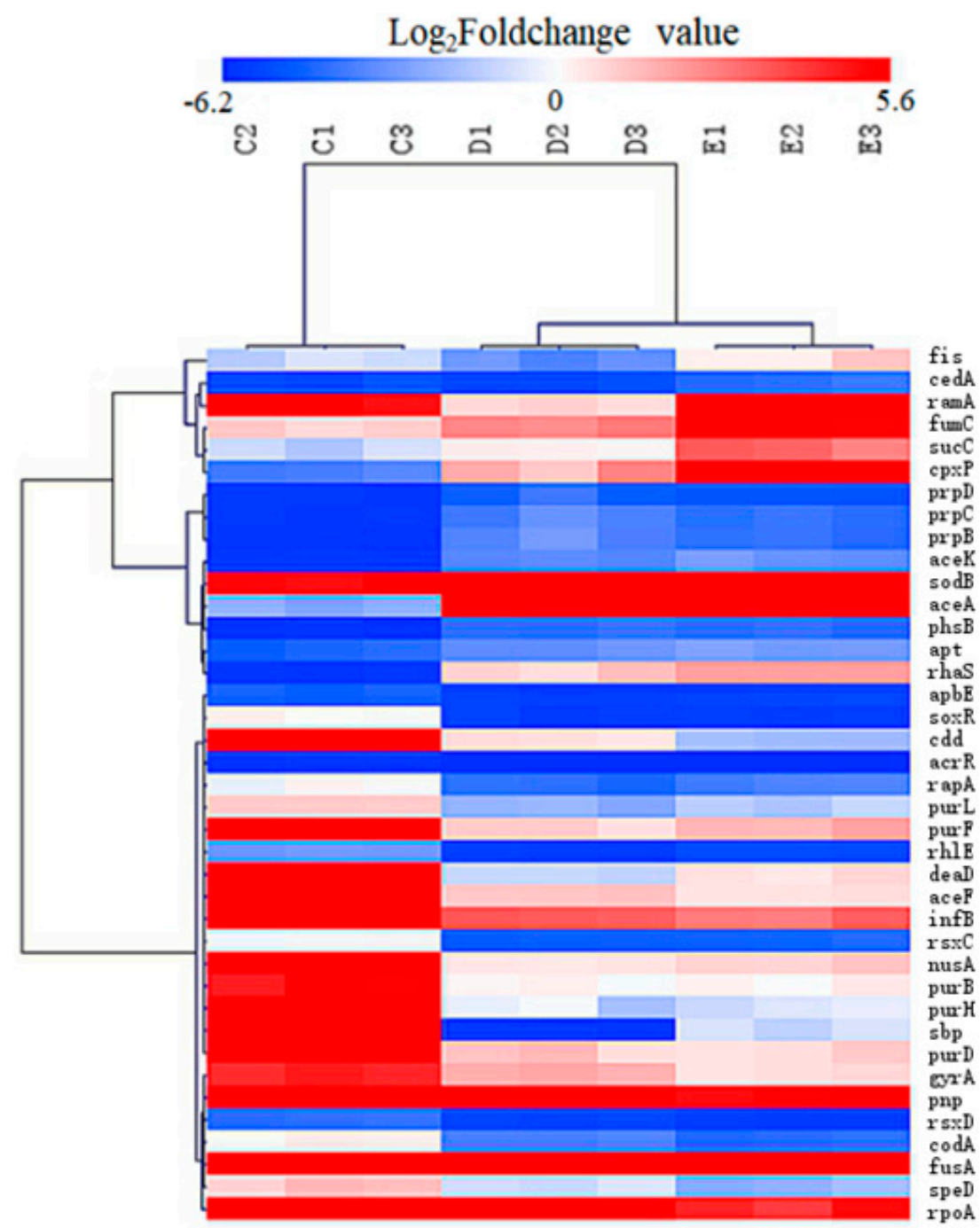

Figure 5. Heatmap of the candidate key genes involved in the sub-MIC induced ENR resistance in S. Enteritidis. " $\mathrm{C}_{1}, \mathrm{C}_{2}, \mathrm{C}_{3}$ ”, “ $\mathrm{D}_{1}, \mathrm{D}_{2}, \mathrm{D}_{3}$ ”, “ $\mathrm{E}_{1}, \mathrm{E}_{2}, \mathrm{E}_{3}$ ” represent triplicate of mutants $32 \mathrm{M}(1 / 2 \mathrm{M})$, $16 \mathrm{M}(1 / 32 \mathrm{M})$ and $8 \mathrm{M}(1 / 128 \mathrm{M})$; "red colour" represents gene up-regulation, "blue colour" represents gene down-regulation, and the shade of the color indicates the degree of gene expression.

The 573 co-DEGs were blasted in the CARD database, and the results showed that there were 19 known drug resistance genes (Table 3). 
Table 3. Resistance-related DEGs blasted in the CARD.

\begin{tabular}{|c|c|c|c|c|}
\hline \multirow{2}{*}{ Gene Name } & \multicolumn{3}{|c|}{ Fold Change } & \multirow{2}{*}{ Non-Redundant Protein Sequence Description } \\
\hline & C vs. B & D vs. B & Evs. B & \\
\hline $\operatorname{ram} A$ & 14.52 & 6.24 & 47.54 & Transcriptional activator RamA \\
\hline rpoB & 10.30 & 5.45 & 3.48 & Hypothetical protein SARI_03509 \\
\hline fusA & 9.80 & 5.49 & 4.45 & Elongation factor $\mathrm{G}^{-}$ \\
\hline$r p s L$ & 9.62 & 3.20 & 2.84 & $30 \mathrm{~S}$ ribosomal protein $\mathrm{S} 12$ \\
\hline typA & 6.54 & 2.89 & 3.31 & Ribosome-dependent GTPase TypA \\
\hline lepB & 6.52 & 3.86 & 3.66 & Signal peptidase I \\
\hline acr $B$ & 6.16 & 4.83 & 4.66 & Multidrug efflux RND transporter permease subunit \\
\hline rplu & 5.80 & 2.88 & 5.38 & 50 S ribosomal protein L21 \\
\hline gyrA & 4.98 & 3.38 & 2.24 & DNA topoisomerase (ATP-hydrolyzing) subunit A \\
\hline rpoc & 4.75 & 3.78 & 3.94 & DNA-directed RNA polymerase subunit beta \\
\hline ompC & 4.66 & 4.67 & 3.93 & Porin OmpC \\
\hline acre & 4.52 & 9.16 & 7.65 & Efflux RND transporter periplasmic adaptor subunit \\
\hline$r s x E$ & 3.95 & 2.19 & 2.39 & Electron transport complex subunit E \\
\hline gyrB & 3.91 & 2.26 & 2.12 & DNA gyrase subunit B \\
\hline soxR & 3.58 & -3.45 & -3.57 & Redox-sensitive transcriptional activator SoxR \\
\hline betI & 2.77 & 2.69 & 4.50 & TetR/AcrR family transcriptional regulator \\
\hline $\operatorname{acr} A$ & 2.46 & 2.15 & 2.32 & $\begin{array}{l}\text { Multidrug efflux RND transporter periplasmic adaptor } \\
\text { subunit AcrA }\end{array}$ \\
\hline $\operatorname{acr} R$ & 2.02 & -5.26 & -4.17 & TetR-family transcriptional regulator \\
\hline 1_00145 & -5.56 & -3.85 & -2.50 & Cryptic aminoglycoside $\mathrm{N}$-acetyltransferase AAC $\left(6^{\prime}\right)$-Iy/Iaa \\
\hline
\end{tabular}

Note: "B", "C", “ $\mathrm{D}$ ", and "E" represent parental strain, mutants 32M (1/2M), 16M (1/32M) and 8M (1/128M), respectively.

Based on the results of the transcriptomic analysis, the expression of the OMPs and MDR efflux pump transporter genes were presented in Table 4. The mRNA expression of OMPs (OmpA, OmpC, OmpD, and OmpF) was showed that only the ompF downregulated in the reduced susceptibility mutant $8 \mathrm{M}(1 / 128 \mathrm{M})$ and resistant mutant $32 \mathrm{M}$ $(1 / 2 \mathrm{M})$, so the decreasing OMPs permeability would not be a determining factors for mutants with resistance level $\geq 8 \mathrm{MIC}$. Only $a c r A, a c r B, a c r D, a c r E, \operatorname{emr} B, m d f A$, and $m d t B$ genes had a significant up-regulation expression of MDR efflux pump genes compared with the parental strain. However, the MDR efflux pump genes of $a c r F$ and $m d t K$ were not activated in mutants compared with the parental strain. The expression levels of $a c r B$ and $a c r E$ in mutants were much higher than other up-regulation genes; meanwhile, only the AcrAB efflux pump had two up-regulation subunits in all mutants ( $\geq 8 \mathrm{MIC}$ ) compared with the parental strain. Our results indicated that overexpression of $A c r A B$ efflux pump predominantly increase in resistance to ENR in mutants $(\geq 8 \mathrm{MIC})$, whereas AcrD, AcrEF, EmrAB, MdfA and MdtK efflux pump facilitated the reduced susceptibility to ENR in mutants ( $\geq 8 \mathrm{MIC}$ ). These gene expression trends were generally consistent with the qRT-PCR results (Figure 2).

Table 4. Expression levels of MDR efflux pump and OMPs in the transcriptome of $S$. Enteritidis mutants.

\begin{tabular}{|c|c|c|c|c|}
\hline \multirow{2}{*}{ Gene Name } & \multicolumn{3}{|c|}{ Fold Change } & \multirow{2}{*}{ Non-Redundant Protein Sequence Description } \\
\hline & C vs. B & D vs. B & E vs. B & \\
\hline ompA & 1.75 & 2.40 & 2.08 & Membrane protein \\
\hline ompC & 4.66 & 4.67 & 3.93 & Porin OmpC \\
\hline ompD & 1.17 & 15.41 & 6.80 & Porin OmpD \\
\hline ompF & -2.38 & 1.06 & -3.45 & Porin $\mathrm{OmpF}$ \\
\hline$m d s C$ & -1.20 & -1.33 & -1.96 & Multidrug efflux transporter outer membrane subunit MdsC \\
\hline $\operatorname{acr} A$ & 2.46 & 2.15 & 2.32 & $\begin{array}{l}\text { Multidrug efflux RND transporter Periplasmic adaptor } \\
\text { subunit AcrA }\end{array}$ \\
\hline$a c r B$ & 6.16 & 4.83 & 4.66 & Multidrug efflux RND transporter permease subunit \\
\hline tolC & 1.03 & 2.00 & 2.48 & Outer membrane protein TolC \\
\hline$a c r D$ & 1.80 & 2.99 & 4.42 & Multidrug efflux RND transporter permease AcrD \\
\hline acrE & 4.52 & 9.16 & 7.65 & Efflux RND transporter periplasmic adaptor subunit \\
\hline acrF & -1.59 & -1.59 & -1.28 & Multidrug efflux RND transporter permease subunit \\
\hline emrA & 1.22 & 1.34 & 1.12 & $\begin{array}{c}\text { Multidrug efflux MFS transporter periplasmic adaptor } \\
\text { subunit EmrA }\end{array}$ \\
\hline emrB & 1.97 & 2.68 & 2.60 & Multidrug efflux MFS transporter permease subunit EmrB \\
\hline$m d f A$ & 1.33 & 1.88 & 2.98 & MFS transporter \\
\hline$m d t K$ & -1.49 & -1.19 & 1.35 & Multidrug efflux MATE transporter MdtK \\
\hline
\end{tabular}


Table 4. Cont.

\begin{tabular}{|c|c|c|c|c|}
\hline \multirow{2}{*}{ Gene Name } & \multicolumn{3}{|c|}{ Fold Change } & \multirow{2}{*}{ Non-Redundant Protein Sequence Description } \\
\hline & C vs. B & D vs. B & E vs. B & \\
\hline$m d s A$ & -1.79 & -2.22 & -2.08 & $\begin{array}{c}\text { Multidrug efflux RND transporter periplasmic adaptor } \\
\text { subunit MdsA }\end{array}$ \\
\hline$m d s B$ & -2.00 & -2.08 & -2.44 & Multidrug efflux RND transporter permease subunit MdsB \\
\hline$m d t A$ & 1.19 & -1.37 & 1.13 & Multidrug efflux RND transporter subunit MdtA \\
\hline$m d t B$ & 1.64 & 1.52 & 2.63 & Multidrug efflux RND transporter permease subunit MdtB \\
\hline$m d t C$ & -1.05 & 1.18 & 1.59 & Multidrug efflux RND transporter permease subunit MdtC \\
\hline macA & -1.08 & 1.02 & 1.50 & Macrolide transporter subunit MacA \\
\hline $\operatorname{macB}$ & 1.04 & 1.47 & 1.53 & $\begin{array}{l}\text { Macrolide ABC transporter ATP-binding } \\
\text { protein/permease MacB }\end{array}$ \\
\hline
\end{tabular}

Note: The genes also detected in RT-PCR were shown in bold. "B", "C", " $\mathrm{D}$ ", and " $\mathrm{E}$ " represent parental strain, mutants 32M (1/2M), 16M $(1 / 32 \mathrm{M})$ and $8 \mathrm{M}(1 / 128 \mathrm{M})$, respectively.

\section{Discussion}

This study documented a versatile adaptive response of the $S$. Enteritidis under a longterm exposure to sub-MICs of ENR which resulted in a diversity of phenotypes including OMPs and MDR efflux pumps expression, QRDR mutation and transcriptomic changes. Mutations in the bacteria DNA gyrase ( $g y r A$ and $g y r B$ ) and topoisomerase IV ( $p a r C$ and parE) genes, as well as up-regulation of MDR efflux genes, were known to mediate resistance to FQs [7,22]. In this study, the mutation of gyrA (Ser83Phe, Ser83Tyr, or Asp87Gly) was observed in all mutants except in reduced susceptibility strains of $2 \mathrm{M}(1 / 2 \mathrm{M}), 2 \mathrm{M}$ $(1 / 32 \mathrm{M}), 4 \mathrm{M}(1 / 2 \mathrm{M})$ and $8 \mathrm{M}(1 / 2 \mathrm{M})$ (Table 1$)$. This is consistent with the fact that the most common QRDR mutations occur in the gyrA gene, resulting in substitutions of Ser-83 with Tyr, Phe, or Ala, and of Asp-87 with Asn, Gly, or Tyr in Salmonella isolates [22-24]. Previous studies demonstrated that point mutations were also observed in parC and parE with the concomitant presence of mutation in gyrA of Salmonella Paratyphi isolates with resistance to nalidixic acid [25]. It was also found that clinical Salmonella isolates evolved a high level of ciprofloxacin (CIP) resistance that was accompanied by additional mutations in GyrA and ParE [26]. Interestingly, no mutation was found in gyrB, parC or parE gene in our study, even in the higher level of resistance group ( $\geq 16 \mathrm{MIC}$ ) (Table 1). One possible reason for this phenomenon was that the FQs resistance level of clinical isolates was much higher than the resistance level of the mutants which were selected in our study. Previous research showed that mutations in gyr $A$ and parC genes conferred a measurable fitness advantage over strains without these mutations [27]. According to the growth curve of Salmonella under exposure to a series of sub-MICs of ENR, it was revealed that the greater the selection pressure, the lower growth rates in our observation (Figure S4). The resistance level of mutants in this study was relatively low, so another reason might be that a single mutation in gyrA was sufficient to impose a loss of fitness. In addition, transcriptomic data showed that $g y r A$ and $g y r B$ were up-regulated in all mutants (Table 3 ). It was reported that the expression of gyrA and parC increased significantly in resistant $S$. Typhimurium selected in vivo, but no changes in the expression of these genes were detected in $S$. Typhimurium selected in vitro [12]. Whether the up-regulated expression of these genes was a determinant of FQs resistance possibility required further investigation.

In addition, mechanisms affecting the cell envelope by increased/decreased expression of OMPs and / or efflux of FQs also contributed to the intracellular accumulation of FQs $[21,28]$. In our study, the relative expression of outer membrane-related genes (ompC, $o m p D$ and $o m p F$ ) were all down-regulated in the mutants with resistance level less than $8 \mathrm{MIC}$, and the amount of down-regulation decreased with the increase in resistance level. Previous research showed that alterations in OMPs including disappearance of some or all of these proteins (OmpA, OmpC, OmpD and OmpF) enriched resistance to FQs in Salmonella isolates with the MIC value $\geq 32 \mu \mathrm{g} / \mathrm{mL}$ [7]. However, when the resistance level exceeds $8 \mathrm{MIC}$, the $о m p C$ and $о m p D$ gene were overexpressed in all mutants, while the $o m p F$ gene was still suppressed in all mutants in our results (Figure 2 and Table 4). OmpF has been experimentally determined to be the most important porin in the resistant mutants 
selected by incrementally increasing CIP concentrations in Salmonella [29]. Our data also showed that the down-regulation of $o m p F$ played the most important role in the initial stages of ENR resistance emergence.

It has been reported that the multidrug resistance (MDR) efflux pumps AcrAB-TolC, AcrEF, EmrAB, MdfABC and MdtK contributed to FQ resistance in Salmonella [8]. Our results revealed that AcrEF and MdtK efflux may have little contribution to ENR resistance at early stage, while AcrAB, EmrAB and MdfABC may play an important role in ENR resistance, since the expression level of $a c r B$, emr $B$, mdf $A$ was increased with increased level of FQs resistance and $a c r B$ gene was significantly increased, while the expression of the $a c r F$ and $m d t K$ gene down-regulated as the susceptibility reduced (Figure 2 and Table 4). Different performance of efflux pumps towards FQ pressure was also reported in the previous study that the expression level of $a c r B$ was increased and $a c r F$ decreased in CIP-resistant Salmonella with the MIC value $\geq 2 \mu \mathrm{g} / \mathrm{mL}$ [28].

A previous study has shown that the $a c r A B$ or acrEF genes conferred multidrug resistance to numerous antibiotics, the emr $A B$ gene conferred resistance to novobiocin and nalidixic acid, the $m d f A$ gene conferred resistance to tetracycline, chloramphenicol, norfloxacin and doxorubicin and the $m d t K$ gene conferred resistance to norfloxacin and doxorubicin in S. Typhimurium [30]. Therefore, we speculate that all these efflux pumps can efflux ENR, but there may be differences in substrate affinity between them, resulting in differences in their expression. Although MDR efflux pumps conferred only low-level resistance (2- to 8-fold increase in MIC values) [31,32], AcrB, EmrB, and MdfA were still working together with QRDR mutations beyond $16 \times \mathrm{MIC}$ resistance levels. It was demonstrated in our results that as the expression of OMPs down-regulated, the expression level of $a c r B, e m r B, m d f A$ were up-regulated, indicating OMP and MDR efflux pumps work alternately.

It was demonstrated that a feedback mechanism between nine homologous functional efflux pump genes through co-regulation of $\operatorname{ram} A$ and $\operatorname{mar} A$ was found in $S$. Typhimurium $[33,34]$. The marbox operon is responsible for producing the $\operatorname{mar} A$, soxR $S$ and $\operatorname{ram} A$ transcriptional activator to activate $a c r A B$ transcription. However, $a c r R$ is independent of mar-sox-rob for controlling the expression of acrB in Salmonella [7,35]. In our study, $\operatorname{ram} A$ were overexpressed in all mutants, while sox $R$ and $\operatorname{acr} R$ gene were up-regulated in resistant mutant $32 \mathrm{M}(1 / 2 \mathrm{M})$, but down-regulated in reduced susceptible mutant $8 \mathrm{M}$ $(1 / 128 \mathrm{M})$, resistant mutant $16 \mathrm{M}(1 / 32 \mathrm{M})$ (Table S2). The overexpression of mar $A$ was only observed in resistant mutant 32M (1/2M), but difference expression in reduced susceptible mutant $8 \mathrm{M}(1 / 128 \mathrm{M})$, resistant mutant $16 \mathrm{M}(1 / 32 \mathrm{M})$. The expression of $\operatorname{ram} A$ was consistent with previous studies, and the differential expression of $\operatorname{sox} R, \operatorname{mar} A$ and $a c r R$ genes might be an important reason for the different expression levels of efflux pumps.

Beyond the role of target mutation, OMPs and MDR efflux pumps involved in FQs resistance, there is an increasingly recognized role for cellular processes such as purines metabolism. It was confirmed that purine metabolism is required for DNA and RNA synthesis [36]. A previous study showed that key genes involved in nucleotide biosynthesis were identified, including purA and purD in purine synthesis [37]. Another research showed that purL or purM mutant disrupted purine biosynthesis in Burkholderia [38]. It was also demonstrated that purA gene was up-regulated in olaquindox resistance Escherichia coli (E. coli) [39]. Previous study showed that KEGG pathway of purine metabolism, pyrimidine metabolism was enriched in the proteomics analysis of FQs resistance E. coli [40]. The Cytohubba result showed that purB, purC, purD, purF, purH, purK, purL, purM, purN and purT were the hube genes and MCODE revealed that the main biological processes all involved in purine metabolism in this study (Table 2). This study has revealed that purine metabolism was the highly activate pathway. It remains to be determined whether purine metabolism and the other changes observed in the ENR mutant is a key pathway to FQs resistance. 


\section{Materials and Methods}

\subsection{Bacteria, Drugs, and Reagents}

S. Enteritidis CICC21527 was purchased from China Center of Industrial Culture Collection (Beijing, China). ENR (purity of 94.2\%) was bought from China Institute of Pharmaceutical and Biological Products Inspection (Beijing, China). Luria-Bertani broth (LB) and Tryptone soybean agar (TSA) was purchased from HOPEBIO (Tsingtao, China). Premix Taq was bought from Moralsbio (Wuhan, China), and Ex TaqTm DNA Polymerase and SYBR was bought from Vazyme Biotech (Nanjing, China). HiFiScript gDNA Removal RT MasterMix was purchased from Cwbio (Beijing, China), and RNAprep pure Bacteria kit was from Majorbio (Shanghai, China). gDNA Removal RT MasterMix was bought from Cwbio (Beijing, China).

\subsection{Antimicrobial Susceptibility Testing}

The MICs of ENR for wild-type and mutants of S. Enteritidis CICC21527 were determined using the broth micro-dilution method, according to the guidelines of the Clinical and Laboratory Standards Institute (CLSI) [41].

\subsection{In Vitro Selection of Mutants under sub-MICs of ENR}

To select de novo generated mutants, a single colony of $S$. Enteritidis CICC21527 was transferred into $5 \mathrm{~mL}$ of LB broth and incubated at $37^{\circ} \mathrm{C}$ overnight. Fresh cultures of bacteria were serially passaged by 1000-fold dilution in $5 \mathrm{~mL}$ batch cultures every $24 \mathrm{~h}$ for 600 generations (60 passages, 10 generations per passage) in LB medium containing ENR at concentrations of $0.031 \mu \mathrm{g} / \mathrm{mL}(1 / 2 \times \mathrm{MIC}), 0.016 \mu \mathrm{g} / \mathrm{mL}(1 / 4 \times \mathrm{MIC}), 0.008 \mu \mathrm{g} / \mathrm{mL}$ $(1 / 8 \times \mathrm{MIC}), 0.004 \mu \mathrm{g} / \mathrm{mL}(1 / 16 \times \mathrm{MIC}), 0.002 \mu \mathrm{g} / \mathrm{mL}(1 / 32 \times \mathrm{MIC}), 0.001 \mu \mathrm{g} / \mathrm{mL}(1 / 64 \times \mathrm{MIC})$, $0.0005 \mu \mathrm{g} / \mathrm{mL}(1 / 128 \times \mathrm{MIC})$ and the untreated $S$. Enteritidis CICC21527 culture was used as control. The liquid cultures were grown at $37{ }^{\circ} \mathrm{C}$ under aerobic conditions without shaking. For every 100 generations of the bacteria culture, the number of colonies was counted, and the percentage of resistant cells in each culture was monitored by plating approximately $10^{5}$ cells onto LB agar containing different concentrations of ENR as control $(2 \times \mathrm{MIC}, 4 \times \mathrm{MIC}, 8 \times \mathrm{MIC}, 16 \times \mathrm{MIC}, 32 \times \mathrm{MIC}$ and $64 \times \mathrm{MIC})[39,42]$. The MICs of the selected mutants were confirmed by antimicrobial susceptibility testing. The $2 \times \mathrm{MIC}$ mutants selected by $1 / 2 \times \mathrm{MIC}, 1 / 4 \times \mathrm{MIC}, 1 / 8 \times \mathrm{MIC}, 1 / 16 \times \mathrm{MIC}, 1 / 32 \times \mathrm{MIC}, 1 / 64 \times \mathrm{MIC}$ and $1 / 128 \times \mathrm{MIC}$ of ENR were named $2 \mathrm{M}(1 / 2 \mathrm{M}), 2 \mathrm{M}(1 / 4 \mathrm{M}), 2 \mathrm{M}(1 / 8 \mathrm{M}), 2 \mathrm{M}(1 / 16 \mathrm{M})$, $2 \mathrm{M}(1 / 32 \mathrm{M}), 2 \mathrm{M}(1 / 64 \mathrm{M})$ and $2 \mathrm{M}(1 / 128 \mathrm{M})$, respectively. The $4 \times \mathrm{MIC}$ to $32 \times \mathrm{MIC}$ mutants induced by sub-MICs of ENR were also similarly named. The mutants were grouped as reduced susceptibility $(\mathrm{MIC}=0.125-0.5 \mu \mathrm{g} / \mathrm{mL})$ and resistance (MIC $\geq 1 \mu \mathrm{g} / \mathrm{mL}$ ), according to the reference of Hong et al. [43].

\subsection{Sequence Analysis of $Q R D R$ Region in gyr $A$, gyrB, parC, and parE Genes}

Strains 2M (1/2M), 2M (1/8M), 2M (1/32M), 2M (1/128M), 4M (1/2M), 4M (1/8M), $4 \mathrm{M}(1 / 32 \mathrm{M}), 4 \mathrm{M}(1 / 128 \mathrm{M}), 8 \mathrm{M}(1 / 2 \mathrm{M}), 8 \mathrm{M}(1 / 8 \mathrm{M}), 8 \mathrm{M}(1 / 32 \mathrm{M}), 8 \mathrm{M}(1 / 128 \mathrm{M}), 16 \mathrm{M}$ $(1 / 2 \mathrm{M}), 16 \mathrm{M}(1 / 8 \mathrm{M}), 16 \mathrm{M}(1 / 32 \mathrm{M})$ and $32 \mathrm{M}(1 / 2 \mathrm{M})$ were applied to the detection of the QRDR region in $g y r A, g y r B$, parC, and parE, according to Kim et al. [22]. The PCR products were purified from agarose gels using a TIANgel Purification Kit (TianGen BioTech Co. Ltd., Beijing, China), followed by nucleotide sequencing performed by Sangon Biotech (Shanghai) Co. Ltd., China. The sequencing results were compared with the genome sequence of S. Enteritidis CICC21527 (SRA Accession No. SRR14246558).

\subsection{Examination of the Expression Levels of OMPs and MDR Efflux Pump Transporters}

The strains as described in Section 2.4 were subjected to gene expression analysis of $\operatorname{omp} C, \operatorname{ompD}, o m p F, a c r B, a c r F, e m r B, m d f A$, and $m d t K$. Total RNA was harvested from $1 \mathrm{~mL}$ aliquots of culture using RNAprep pure Bacteria kit according to the manufacturer's recommendation. DNA in total RNA was removed by treatment with HiFiScript gDNA Removal RT MasterMix and cDNA synthesis was performed using HiFiScript gDNA 
Removal cDNA Synthesis Kit according to the method described in the manufacturer. qRT-PCR amplification was conducted with an initial step of $5 \mathrm{~min}$ at $95^{\circ} \mathrm{C}$, followed by 40 cycles of $10 \mathrm{~s}$ at $95^{\circ} \mathrm{C}, 30 \mathrm{~s}$ at the annealing temperature at $60^{\circ} \mathrm{C}$. The gap $A$ gene was used as an internal control for normalization, and the parental strains were used as references for their derived mutants. The $2^{-\Delta \Delta C T}$ method was used for relative gene expression calculations. Each RNA sample was tested in triplicate and the primers used were listed in Table S1.

\subsection{RNA Sequencing and Bioinformatic Analysis}

The total RNA of parental $S$. Enteritidis CICC21527, reduced susceptibility mutant $8 \mathrm{M}(1 / 128 \mathrm{M})$, resistant mutants $16 \mathrm{M}(1 / 8 \mathrm{M})$ and $32 \mathrm{M}(1 / 2 \mathrm{M})$ was processed as the reference described [39]. The samples were paired-end sequenced using an Illumina HiSeq ${ }^{\mathrm{TM}}$ 2000 system (Personalbio technology Co. Ltd., Nanjing, China). The reference genome for annotation was S. Enteritidis CICC21527 genome (SRA Accession No. SRR14246558). The sequencing data were submitted to the National Center for Biotechnology Information Sequence Read Archive (SRA) under Accession No. PRJNA700473.

To characterize the biological pathways associated with the co-DEGs of ENR resistance, co-DEGs were analyzed in the ClueGO. The Retrieval of Interacting Genes database online tool (STRING; http:/ / stringdb.org/, accessed on 27 July 2021) was used to analyze the PPI of DEGs, and those experimentally validated interactions with a combined score $>0.4$ were selected as significant. The screened networks were visualized by Cytoscape 3.8.0. The Cytohubba was used to check the hub genes and the MCODE was performed to establish PPI network modules, Degree cutoff $=2$, Node score cutoff $=0.2$, -core $=2$, Max . Depth $=100$ as selected.

\section{Conclusions}

In summary, this study shows an evolutionary process for Salmonella on FQs resistance. Mutants firstly decreased OMPs permeability to rapidly adapt the selected pressure circumstances in the initial stage of resistance emergence, then the expression of efflux pumps was up-regulated in the following process and QRDR mutation was obtained, resulting in a higher resistance level under a long-term selected pressure of the sub-MIC antibiotics in vitro. Hub genes (purB, purC, purD, purF, purH, purK, purL, purM, purN and purT) and the remarkable biological processes of purine metabolism were identified of transcriptomic profiles. This suggests that changes in FQs resistance based on gene expression patterns and metabolic pathways. However, the interplay between FQs resistance mechanisms and metabolic pathway requires further exploration.

Supplementary Materials: The following are available online at https:/ / www.mdpi.com/article/10 .3390/ijms222212218/s1.

Author Contributions: Conceptualization, G.C. and Y.G.; methodology, Y.G. and C.W.; software, Y.G.; validation, L.H., C.W. and J.H.; formal analysis, Y.G. and G.C.; investigation, Y.G.; resources, L.H.; data curation, L.H., Y.G.; writing-original draft preparation, Y.G.; writing—review and editing, Y.G., G.C., H.H.; visualization, Y.G.; supervision, G.C.; project administration, G.C. and Z.Y.; funding acquisition, G.C. All authors have read and agreed to the published version of the manuscript.

Funding: This research was funded by the National Natural Science Foundation of China (grant number 32072921 and 31502115) and Surveillance program for antimicrobial resistance in bacteria of animal origin, Ministry of Agriculture and Rural Affairs of P.R.China (grant number 161901600).

Institutional Review Board Statement: Not applicable.

Informed Consent Statement: Not applicable.

Data Availability Statement: The sequencing data was submitted to the National Center for Biotechnology Information Sequence Read Archive (SRA) under Accession No. PRJNA700473.

Conflicts of Interest: The authors declare that the research was conducted in the absence of any commercial or financial relationships that could be construed as a potential conflict of interest. 


\section{References}

1. Hoffmann, M.; Zhao, S.; Pettengill, J.; Luo, Y.; Monday, S.R.; Abbott, J.; Ayers, S.L.; Cinar, H.N.; Tim Muruvanda, T.; Li, C.; et al. Comparative Genomic Analysis and Virulence Differences in Closely Related Salmonella enterica Serotype Heidelberg Isolates from Humans, Retail Meats, and Animals. Genome Biol. Evol. 2014, 6, 1046-1068. [CrossRef] [PubMed]

2. Hendriksen, R.S.; Vieira, A.R.; Karlsmose, S.; Lo Fo Wong, D.M.; Jensen, A.B.; Wegener, H.C.; Aarestrup, F.M. Global monitoring of Salmonella serovar distribution from the World Health Organization Global Foodborne Infections Network Country Data Bank: Results of quality assured laboratories from 2001 to 2007. Foodborne Pathog. Dis. 2011, 8, 887-900. [CrossRef]

3. Martinez, M.; Mcdermott, P.; Walker, R. Pharmacology of the fluoroquinolones: A perspective for the use in domestic animals. Vet. J. 2006, 172, 10-28. [CrossRef] [PubMed]

4. Hopkins, K.L.; Davies, R.H.; Threlfall, E.J. Mechanisms of quinolone resistance in Escherichia coli and Salmonella: Recent developments. Int. J. Antimicrob. Agent 2005, 25, 358-373. [CrossRef] [PubMed]

5. Lo, N.W.S.; Chu, M.T.; Ling, J.M. Increasing quinolone resistance and multidrug resistant isolates among Salmonella enterica in Hong Kong. J. Infect. 2012, 65, 528-540. [CrossRef] [PubMed]

6. Fábrega, A.; Madurga, S.; Giralt, E.; Vila, J. Mechanism of action of and resistance to quinolones. Microb. Biotechnol. 2009, 2, 40-61. [CrossRef]

7. Rushdy, A.A.; Mabrouk, M.I.; Abu-Sef FA, H.; Kheiralla, Z.H.; Abdel-All, S.M.; Saleh, N.M. Contribution of different mechanisms to the resistance to fluoroquinolones in clinical isolates of Salmonella enterica. Braz. J. Infect. Dis. 2013, 17, 431-437. [CrossRef] [PubMed]

8. Nishino, K.; Latifi, T.; Groisman, E.A. Virulence and drug resistance roles of multidrug efflux systems of Salmonella enterica serovar Typhimurium. Mol. Microbiol. 2010, 59, 126-141. [CrossRef] [PubMed]

9. Yamasaki, S.; Nagasawa, S.; Fukushima, A.; Hayashi-Nishino, M.; Nishino, K. Cooperation of the multidrug efflux pump and lipopolysaccharides in the intrinsic antibiotic resistance of Salmonella enterica serovar Typhimurium. J. Antimicrob. Chemother. 2013, 68, 1066-1070. [CrossRef]

10. Andersson, D.I.; Hughes, D. Microbiological effects of sublethal levels of antibiotics. Nat. Rev. Microbiol. 2014, 12, 465. [CrossRef] [PubMed]

11. Chow, L.K.M.; Ghaly, T.M.; Gillings, M. A survey of sub-inhibitory concentrations of antibiotics in the environment. J. Environ. 2021, 99, 21-27. [CrossRef]

12. Li, L.; Dai, X.; Wang, Y.; Yang, Y.; Zhao, X.; Wang, L.; Zeng, M. RNA-seq-based analysis of drug-resistant Salmonella enterica serovar Typhimurium selected in vivo and in vitro. PLoS ONE 2017, 12, e0175234. [CrossRef]

13. van der Horst, M.A.; Schuurmans, J.M.; Smid, M.C.; Koenders, B.B.; ter Kuile, B.H. De novo acquisition of resistance to three antibiotics by Escherichia coli. Microb. Drug Resist. 2011, 17, 141-147. [CrossRef] [PubMed]

14. Thi, T.D.; López, E.; Rodríguez-Rojas, A.; Rodríguez-Beltrán, J.; Couce, A.; Guelfo, J.R.; Castañeda-García, A.; Blázquez, J. Effect of recA inactivation on mutagenesis of Escherichia coli exposed to sublethal concentrations of antimicrobials. J. Antimicrob. Chemother. 2011, 66, 531. [CrossRef]

15. Kohanski, M.A.; Depristo, M.A.; Collins, J.J. Sublethal antibiotic treatment leads to multidrug resistance via radical-induced mutagenesis. Mol. Cell 2010, 37, 311-320. [CrossRef] [PubMed]

16. Balashov, S.; Humayun, M.Z. Mistranslation induced by streptomycin provokes a RecABC/RuvABC-dependent mutator phenotype in Escherichia coli cells. J. Mol. Biol. 2002, 315, 513-527. [CrossRef] [PubMed]

17. López, E.; Elez, M.; Matic, I.; Blázquez, J. Antibiotic-mediated recombination: Ciprofloxacin stimulates SOS-independent recombination of divergent sequences in Escherichia coli. Mol. Microbiol. 2010, 64, 83-93. [CrossRef] [PubMed]

18. Beaber, J.W.; Hochhut, B.; Waldor, M.K. SOS response promotes horizontal dissemination of antibiotic resistance genes. Nature 2004, 427, 72-74. [CrossRef]

19. Wistrand-Yuen, E.; Knopp, M.; Hjort, K.; Koskiniemi, S.; Berg, O.G.; Andersson, D.I. Evolution of high-level resistance during low-level antibiotic exposure. Nat. Commun. 2018, 9, 1599. [CrossRef] [PubMed]

20. Zhang, C.Z.; Ren, S.Q.; Chang, M.X.; Chen, P.X.; Ding, H.Z.; Jiang, H.X. Resistance mechanisms and fitness of Salmonella Typhimurium and Salmonella Enteritidis mutants evolved under selection with ciprofloxacin in vitro. Sci. Rep. 2017, 7, 9113. [CrossRef]

21. Dawan, J.; Uddin, M.J.; Ahn, J. Development of de novo resistance in Salmonella Typhimurium treated with antibiotic combinations. FEMS Microbiol. Lett. 2019, 366, fnz127. [CrossRef]

22. Kim, S.Y.; Lee, S.K.; Park, M.S.; Na, H.T. Analysis of the Fluoroquinolone Antibiotic Resistance Mechanism of Salmonella enterica Isolates. J. Microbiol. Biotechnol. 2016, 26, 1605-1612. [CrossRef]

23. Dimitrov, T.; Dashti, A.A.; Albaksami, O.; Udo, E.E.; Jadaon, M.M.; Albert, M.J. Ciprofloxacin-resistant Salmonella enterica serovar typhi from Kuwait with novel mutations in gyrA and parC genes. J. Clin. Microbiol. 2009, 47, 208-211. [CrossRef]

24. O'Regan, E.; Quinn, T.; Pagès, J.M.; McCusker, M.; Piddock, L.; Fanning, S. Multiple regulatory pathways associated with high-level ciprofloxacin and multidrug resistance in Salmonella enterica serovar enteritidis: Involvement of RamA and other global regulators. Antimicrob. Agents Chemother. 2009, 53, 1080-1087. [CrossRef] [PubMed]

25. Qian, H.; Cheng, S.; Liu, G.; Tan, Z.; Dong, C.; Bao, J.; Hong, J.; Jin, D.; Bao, C.; Gu, B. Discovery of seven novel mutations of gyrB, parC and parE in Salmonella Typhi and Paratyphi strains from Jiangsu Province of China. Sci. Rep. 2020, 10, 7359. [CrossRef]

26. Baucheron, S.; Chaslus-Dancla, E.; Cloeckaert, A.; Chiu, C.H.; Butaye, P. High-Level Resistance to Fluoroquinolones Linked to Mutations in gyrA, parC, and parE in Salmonella enterica Serovar Schwarzengrund Isolates from Humans in Taiwan. Antimicrob. Agents Chemother. 2005, 49, 862-863. [CrossRef] [PubMed]

27. Baker, S.; Duy, P.T.; Nga, T.V.T.; Dung, T.T.N.; Phat, V.V.; Chau, T.T.; Turner, A.K.; Farrar, J.; Boni, M.F. Fitness benefits in fluoroquinolone-resistant Salmonella Typhi in the absence of antimicrobial pressure. eLife 2013, 2, e01229. [CrossRef] [PubMed] 
28. Kang, H.W.; Woo, G.J. Increase of multidrug efflux pump expression in fluoroquinolone-resistant Salmonella mutants induced by ciprofloxacin selective pressure. Res. Vet. Sci. 2014, 97, 182-186. [CrossRef]

29. Du, X.; Liu, Y.; Sun, X.; Zhao, J.; Wang, J.; Li, J.; Liu, X.; Wang, J.; Li, Y. The mRNA expression of ompF, invA and invE was associated with the ciprofloxacin-resistance in Salmonella. Arch. Microbiol. 2020, 202, 2263-2268. [CrossRef]

30. Tsukasa, H.; Akihito, Y.; Kunihiko, N. TolC dependency of multidrug efflux systems in Salmonella enterica serovar Typhimurium. J. Antimicrob. Chemother. 2010, 65, 1372-1376.

31. Singh, R.; Swick, M.C.; Ledesma, K.R.; Yang, Z.; Hu, M.; Zechiedrich, L.; Tam, V.H. Temporal Interplay between Efflux Pumps and Target Mutations in Development of Antibiotic Resistance in Escherichia coli. Antimicrob. Agents Chemother. 2012, 56, 1680-1685. [CrossRef] [PubMed]

32. Chang, T.M.; Lu, P.L.; Li, H.H.; Chang, C.Y.; Chen, T.C.; Chang, L.L. Characterization of Fluoroquinolone Resistance Mechanisms and Their Correlation with the Degree of Resistance to Clinically Used Fluoroquinolones among Escherichia coli Isolates. J. Chemother. 2007, 19, 488-494. [CrossRef] [PubMed]

33. Zhang, C.Z.; Chen, P.X.; Yang, L.; Li, W.; Chang, M.X.; Jiang, H.X. Coordinated Expression of acrAB-tolC and Eight Other Functional Efflux Pumps through Activating ramA and marA in Salmonella enterica serovar Typhimurium. Microb. Drug Resist. 2018, 24, 120-125. [CrossRef] [PubMed]

34. Blair, J.M.; Smith, H.E.; Ricci, V.; Lawler, A.J.; Thompson, L.J.; Piddock, L.J. Expression of homologous RND efflux pump genes is dependent upon AcrB expression: Implications for efflux and virulence inhibitor design. J. Antimicrob. Chemother. 2014, 2, 424-431. [CrossRef] [PubMed]

35. Yamasaki, S.; Nikaido, E.; Nakashima, R.; Sakurai, K.; Fujiwara, D.; Fujii, I.; Nishino, K. The crystal structure of multidrugresistance regulator RamR with multiple drugs. Nat. Commun. 2013, 4, 2078. [CrossRef] [PubMed]

36. Switzer, R.L.; Zalkin, H.; Saxild, H.H. Purine, Pyrimidine, and Pyridine Nucleotide Metabolism; John Wiley \& Sons, Ltd.: Hoboken, NJ, USA, 2014

37. Le Breton, Y.; Mistry, P.; Valdes, K.M.; Quigley, J.; Kumar, N.; Tettelin, H.; McIver, K.S. Genome-wide identification of genes required for fitness of group A Streptococcus in human blood. Infect. Immun. 2013, 81, 862-875. [CrossRef]

38. Kim, J.K.; Am Jang, H.; Won, Y.J.; Kikuchi, Y.; Han, S.H.; Kim, C.H.; Nikoh, N.; Fukatsu, T.; Lee, B.L. Purine biosynthesis-deficient Burkholderia mutants are incapable of symbiotic accommodation in the stinkbug. ISME J. 2014, 8, 552. [CrossRef]

39. Gu, Y.; Wang, S.; Huang, L.; Sa, W.; Li, J.; Huang, J.; Dai, M.; Cheng, G. Development of Resistance in Escherichia coli ATCC25922 under Exposure of Sub-Inhibitory Concentration of Olaquindox. Antibiotics 2020, 9, 791. [CrossRef] [PubMed]

40. Du, G.F.; Zheng, Y.D.; Chen, J.; He, Q.Y.; Sun, X. Novel Mechanistic Insights into Bacterial Fluoroquinolone Resistance. J. Proteome Res. 2019, 18, 3955-3966. [CrossRef]

41. Clinical and Laboratory Standards Institute (CLSI). Performance Standards for Antimicrobial Susceptibility Testing: Twenty-Four Informational Supplement. CLSI document M100-S24; CLSI: Wayne, NJ, USA, 2011; Volume 34.

42. Gullberg, E.; Cao, S.; Berg, O.G.; Ilbäck, C.; Sandegren, L.; Hughes, D.; Andersson, D.I. Selection of Resistant Bacteria at Very Low Antibiotic Concentrations. PLoS Pathog. 2011, 7, e1002158. [CrossRef]

43. Hong, S.; Rovira, A.; Davies, P.; Ahlstrom, C.; Muellner, P.; Rendahl, A.; Olsen, K.; Bender, J.B.; Wells, S.; Perez, A.; et al. Serotypes and Antimicrobial Resistance in Salmonella enterica Recovered from Clinical Samples from Cattle and Swine in Minnesota, 2006 to 2015. PLoS ONE 2016, 11, e0168016. [CrossRef] [PubMed] 